\title{
Os parlamentos e as relações internacionais
}

\section{LÚCIO ALCÂNTARA*}

Os parlamentos têm tido tradicionalmente, pouca participação na formulação das políticas externas nacionais. Sob o pretexto de que a política externa é "assunto de príncipes e não do povo”, ao longo de sua história, os parlamentos têm estado alijados do tema. Neste sentido, pode-se dizer que as conquistas democráticas progrediram pouco neste final de século, uma vez que os próprios teóricos do Direito Constitucional, ao deixarem de questionar as idéias herdadas ao longo da lenta evolução do sistema democrático-representativo de governo, não pareceram encontrar, até hoje, qualquer utilidade para a participação popular na condução das relações internacionais. Entretanto, a história contemporânea vem se encarregando de demonstrar os perigos de tal concepção.

Por um lado, sabe-se que, em razão da complexidade das relações intergovernamentais e dos aspectos extremamente específicos que as caracterizam, torna-se, em determinados momentos, inconveniente o debate público da política externa nacional. A relação entre Estados soberanos é extremamente delicada em suas múltiplas nuances. Por outro lado, entretanto, a última década do século XX trouxe profundas transformações à própria natureza das relações internacionais. Se antes eram a segurança e as questões bélicas o ponto focal da formulação das políticas externas nacionais, no que os teóricos das relações internacionais costumavam chamar de high politics, hoje foram os temas da low politics como o comércio internacional, o meio ambiente e os direitos humanos, alçados ao primeiro plano nos foros negociadores internacionais. Tal transformação, aliada ao notável avanço verificado no campo das comunicações, gerou uma demanda entre os atores sociais e agentes econômicos por uma maior transparência na formulação das políticas externas nacionais, tradicionalmente reservadas à condução, muitas vezes cercada de segredo, pelas instâncias competentes do Poder Executivo.

\section{O caso brasileiro}

No caso do Brasil, a Constituição de 1988 atribui ao Poder Executivo competência privativa para manter relações com Estados estrangeiros e acreditar

* Senador da República Federativa do Brasil. Presidente da Comissão de Assuntos Econômicos do Senado. 
seus representantes diplomáticos, bem como para celebrar tratados, convenções e atos internacionais, sujeitos a referendo do Congresso Nacional (art. 54, incisos VII e VIII). Ao Parlamento cabe aprovar os atos internacionais firmados pelo Presidente da República ou seu Plenipotenciário, à luz do art. 49, inciso I, cabendolhe, também, segundo o inciso II, autorizar o Presidente da República a declarar guerra e celebrar a paz, conforme segue:
Art. 49. É da competência exclusiva do Congresso Nacional:
I - resolver definitivamente sobre tratados, acordos ou atos internacionais que acarretem encargos ou compromissos gravosos ao patrimônio nacional;
II - autorizar o Presidente da República a declarar guerra, a celebrar a paz, a permitir que forças estrangeiras transitem pelo território nacional ou nele permaneçam temporariamente, ressalvados os casos previstos em lei complementar; (...)

No que tange à aprovação de tratados e demais atos internacionais, o procedimento parlamentar tem se limitado apenas a sua aprovação ou rejeição in totum. Isto porque, tendo em vista óbvias razões de ordem prática, não seria possível a um país aprovar emendas a um tratado internacional negociado em âmbito multilateral. Com efeito, tal prática, se adotada por todos os Estados contratantes, haveria de gerar um completo caos na convivência internacional, tornando impossível, do ponto de vista prático, qualquer previsibilidade quanto à ratificação ou modificação de textos acordados ao longo de inúmeras reuniões e muitas vezes difíceis negociações.

Assim, terminada a negociação de um tratado, tem o Presidente da República, que a iniciara, a faculdade de dar ou não prosseguimento ao processo de sua internalização no Direito Interno. Com exceção das convenções internacionais do trabalho, que por sua natureza obrigam a sua submissão à aprovação do Parlamento Nacional, nos demais casos tanto pode o chefe do governo mandar arquivar o produto de uma negociação bilateral ou coletiva, se o julgar insatisfatório, quanto determinar estudos mais aprofundados na área do Executivo, e submeter, quando melhor lhe pareça, o texto à aprovação congressual. ${ }^{1}$

Os recentes esquemas de integração regional, como o Mercosul, representam, entretanto, casos especialíssimos, uma vez que seus instrumentos jurídicos emergem de um Acordo-Quadro anterior, como é o Tratado de Assunção, o qual proclama a intenção inequívoca dos Estados membros de procederem a um processo de integração, para o qual faz-se necessária a celebração de vários protocolos adicionais ao Acordo inicial. Assim sendo, a presunção é a de que é do interesse dos Estados signatários a célere aprovação congressual dos atos internacionais firmados no âmbito do processo integracionista. 
Na prática, entretanto, isso nem sempre ocorre. Por vezes o instrumento negociado acaba por sofrer restrições de setores interessados e os Governos optam por sustar a sua tramitação no Congresso Nacional. Exemplo disso é o Código Aduaneiro do Mercosul, que, aprovado pela Câmara dos Deputados, aguarda há aproximadamente dois anos o seu exame pela Comissão de Relações Exteriores do Senado, enquanto certos detalhes técnicos são renegociados.

Se em nenhum caso poderá o Presidente da República manifestar o consentimento definitivo em relação ao tratado sem a aprovação do Congresso Nacional, por outro lado, tal aprovação não o obriga à ratificação. Conforme assinala Francisco Rezek, "Isto significa, noutras palavras, que a vontade nacional, afirmativa quanto à assunção de um compromisso externo, repousa sobre a vontade conjugada dos dois poderes políticos. A vontade individualizada de cada um deles é necessária, mas não suficiente" .

A decisão do Congresso Nacional é formalizada por meio de um decreto legislativo, promulgado pelo presidente do Senado Federal, e publicado no Diário Oficial da União. O decreto legislativo não rejeita nem altera o tratado. Exemplos de rejeição são raríssimos, mas, nesse caso, caberia apenas uma comunicação, mediante mensagem, ao Presidente da República. Entre os raros casos de desaprovação pode-se destacar, a título de exemplo, o tratado argentino-brasileiro de 25 de janeiro de 1890, sobre a fronteira das Missões, rejeitado pelo plenário do Congresso em 18 de agosto de 1891, por cento e quarenta e dois votos contra cinco ${ }^{3}$.

A doutrina diverge no que diz respeito à possibilidade de alteração do tratado quando de sua tramitação no Congresso Nacional. Sustenta uma das correntes que, caso o tratado admita reservas, poderá o Congresso Nacional aproválo com restrições, as quais o Poder Executivo traduzirá em reservas no momento da ratificação. Do mesmo modo, poderá aprová-lo com declaração de desabono às reservas acaso feitas na assinatura, e que deixarão de ser confirmadas, portanto, na ratificação. Foi neste sentido o parecer de 1962 do jurista Haroldo Valladão, quando consultor jurídico do Itamaraty ${ }^{4}$.

Alguns fatos históricos narrados pelo Prof. Amado Luiz Cervo permitem supor que, à época do regime monárquico no Brasil, o Poder Legislativo desempenhava um papel de maior protagonismo na formulação de nossa política externa. Considerando o Tratado de Comércio e Navegação firmado com a Inglaterra em 1827, assim como um certo número de outros instrumentos comerciais, celebrados à época da independência, lesivos aos interesses nacionais, o Senado não hesitou em rejeitar por unanimidade a renovação do Tratado de Comércio com a Áustria daquele mesmo ano. Assim também foi rejeitado pela Câmara dos Deputados o Tratado de Comércio com Portugal, celebrado em 1836, que nem sequer passou pelo crivo do Senado. A rejeição destes tratados pelo Parlamento exerceu notável influência sobre a formulação de diretrizes de nossa política externa, levando o Governo a não mais 
celebrar tratados de comércio com as grandes potências, visto que elas não observavam o princípio da reciprocidade e que faziam valer as estipulações apenas a seu favor ${ }^{5}$.

Mais uma vez faz-se necessário distinguir, neste contexto, os atos internacionais advindos do processo de integração dos demais. Os teóricos da integração concordam quanto ao status especialíssimo que assumem os Estados participantes de tal processo, em relação a terceiros países ${ }^{6}$. Em seminário realizado pelo Conselho Brasileiro de Relações Internacionais e pela USP em São Paulo, em 1993, o jurista Luiz Olavo Baptista assinalava que, no processo de negociações do Mercosul, vem ocorrendo um curioso fato no que diz respeito a determinadas matérias de âmbito interno: decisões vêm sendo tomadas pelos negociadores do Mercosul em nível quadripartite, e internalizadas por via de portarias ministeriais, de tal forma que o centro de decisões é transferido, por vezes, para um foro intergovernamental, com prejuízo da competência legislativa do Congresso Nacional, que sequer tem a possibilidade de acompanhar todos estes processos decisórios que se desenrolam nos múltiplos foros negociadores do Mercosul. Trata-se aqui de uma situação sui generis, porém própria dos processos de integração. É interessante ressaltar a existência de uma Comissão Mista do Mercosul no seio do Congresso Nacional, a Comissão é integrada por legisladores representantes do Parlamento Brasileiro na Comissão Parlamentar Conjunta do Mercosul, órgão previsto pelos Tratados de Assunção e pelo Protocolo de Ouro Preto, o qual não dispõe, entretanto, de real poder de controle sobre o processo negociador.

\section{O Senado Federal nas relações exteriores do Brasil}

Ao Senado Federal cabem, especificamente, certas atribuições no campo das relações internacionais conforme preceitos constantes dos incisos IV e V do art. 52 da Constituição Federal. São elas: aprovar previamente, por voto secreto, após argüição em sessão secreta, a escolha dos chefes de missão diplomática de caráter permanente; e autorizar operações externas de natureza financeira, de interesse da União, dos Estados, do Distrito Federal, dos Territórios e dos Municípios.

Quanto à intervenção do Senado na aprovação de embaixadores, é interessante notar o exemplo da recente praxis norte-americana, do uso, pelo Presidente da República, de enviados ou emissários especiais para determinadas regiões. Foi assim que Thomas "Mack” McLarty, amigo pessoal e colaborador do Presidente Clinton, tornou-se o seu “enviado para as Américas”, aqui tendo mantido importantes contatos políticos com vistas à conformação da ALCA. Tal mecanismo permite ao Presidente utilizar pessoa de sua confiança pessoal no desempenho de certas missões de caráter internacional, sem que seu nome necessite de passar, conforme determina a Constituição, pelo crivo do Senado.

A competência para a aprovação de operações externas de natureza financeira foi uma inovação da Constituição Federal de 1988, proposta em virtude 
do surpreendente endividamento externo do País, dívida contraída ao longo de vários anos e sem o conhecimento e controle do Congresso Nacional.

Tanto a Câmara como o Senado possuem comissões especializadas ratione materiae, destinadas ao estudo e análise das matérias a elas encaminhadas, antes da votação em plenário. As matérias relativas às operações externas de natureza financeira, de interesse da União, dos Estados, do Distrito Federal, dos Territórios e dos Municípios, recaem sob a competência da Comissão de Assuntos Econômicos. Já as relações internacionais, em sua dimensão política e comercial, competem à Comissão de Relações Exteriores e Defesa Nacional. O Regimento do Senado atribui também a essa Comissão o tratamento dos temas afeitos à segurança nacional, como as questões fronteiriças, por exemplo.

A par da análise e aprovação dos atos internacionais e da aprovação da escolha feita pelo Presidente da República dos chefes de missão diplomática, cabe à Comissão de Relações Exteriores e Defesa Nacional realizar audiências públicas com entidades da sociedade civil para a coleta de informações sobre temas de sua competência; e convocar Ministros de Estado para prestar informações sobre assuntos inerentes a suas atribuições ${ }^{7}$.

Assim, a Comissão de Relações Exteriores e Defesa Nacional do Senado vem abordando temas como a segurança, particularmente nas áreas fronteiriças da região amazônica, tendo ainda convidado autoridades do Poder Executivo para discutir a implantação de uma área de segurança no Mercosul. Outros temas que constituíram objeto de debate - com a presença de representantes do Ministério das Relações Exteriores - foram a questão da recente tentativa de golpe de Estado no Paraguai, e a guerra dos Bálcãs.

\section{O controle dos atos internacionais em outros países}

Se procedermos a um estudo comparativo do papel dos parlamentos no processo de ratificação dos tratados internacionais e de sua incorporação ao direito interno, verificaremos que a maioria das Constituições nacionais condiciona a ratificação dos atos internacionais à manifestação do Poder Legislativo, atribuindolhes competência, em grau variável, para a aprovação daqueles atos. Em muitos deles, o Presidente da República não poderá ratificar certos tipos de tratados, a não ser com autorização legislativa. É o caso da França, por exemplo.

Em outros países, a Constituição enumera os tipos de tratados que precisam ser aprovados pelo Parlamento para que sejam ratificados. Na Bélgica, por exemplo, os tratados comerciais e aqueles que ensejam qualquer alteração nos direitos civis devem ser submetidos à aprovação parlamentar; em Mônaco, os tratados que possuam algum dispositivo com repercussão constitucional deverão ser aprovados pelo Conselho Nacional; e na Irlanda, similarmente à nossa Constituição Federal de 1988, todos os atos internacionais que envolvam compromissos financeiros 
deverão ser submetidos à aprovação do Parlamento. Na Holanda, a aprovação parlamentar de um tratado internacional será explícita ou tácita. No primeiro caso, um projeto de lei que autoriza a ratificação do tratado é apresentado, discutido e votado de acordo com o procedimento legislativo ordinário. No segundo caso, o Governo envia o texto do tratado às duas Casas, acompanhado de uma carta em que solicita o seu assentimento. Considera-se aprovado o tratado se nenhuma das duas Casas se manifestar no prazo de trinta dias ${ }^{8}$.

O exemplo norte-americano de intervenção parlamentar em matéria de tratados internacionais é dos mais interessantes. Segundo a Constituição dos Estados Unidos da América, todo tratado, para tornar-se definitivo, deverá receber a aprovação do Senado, expressa por pelo menos dois terços dos membros presentes. Essa prerrogativa se explica se considerarmos que o Senado americano, assim como o brasileiro, é o defensor da independência dos Estados Membros da Federação. Sua intervenção limita, portanto, os poderes do Presidente, que deverá buscar o apoio de certos senadores influentes para a condução da política externa ${ }^{9}$. Além dos tratados propriamente ditos, o Presidente pode negociar acordos que não são submetidos à aprovação do Senado. São os chamados acordos executivos. O aumento no uso desse tipo de instrumento pelo Governo norte-americano foi objeto de severo ataque por parte do Senado após o término da Segunda Grande Guerra. Na ocasião, o Governo norte-americano assinara os Tratados de Yalta na forma de acordos executivos. Esses acordos faziam importantes concessões aos soviéticos em detrimento da China. O Senado insurgiu-se particularmente contra o elemento de segredo presente nas tratativas do Governo com outros países, em violação ao próprio espírito da Constituição americana, que condenava energicamente os tratados secretos ${ }^{10}$.

Com o crescimento do interesse popular pelos temas de política externa nos Estados Unidos, estes passaram a atrair as atenções dos parlamentares e a integrar as pautas das campanhas eleitorais. A questão ambiental e a guerra do Vietnã foram, sem dúvida, pontos de inflexão na agenda parlamentar norteamericana.

A atuação do Congresso na formulação da política externa americana veio a fortalecer-se com a importância de que passaram a se revestir, nas últimas décadas, as transações comerciais internacionais. Com efeito, dispõe o Artigo I, Seção VIII, cláusula (3) da Constituição americana que ao Congresso compete (...) "Regular o comércio com as nações estrangeiras, entre os diversos Estados e com as tribos e índios;”"11. Tal competência poderá ser delegada ao Presidente da República por meio da via rápida, ou fast track authority, mecanismo pelo qual o Congresso concede ao Poder Executivo, por um prazo limitado, poderes para negociar um determinado tratado de comércio. Esse mandato, que foi repetidamente negado ao Presidente Clinton, quando o solicitou com vistas às negociações da 
Área de Livre Comércio das Américas (ALCA), vem sendo perseguido pelo presidente Bush na forma da Trade Promotion Authority - TPA.

Já a Constituição da Argentina, cuja reforma levada a cabo em 1994 positivou a supremacia do tratado em relação ao ordenamento jurídico interno, nos termos do artigo 75, incisos 22 e 24, manteve, ainda assim, o controle dos atos internacionais pelo Congresso Nacional, salvo no que diz respeito àqueles tratados que versem sobre matéria da competência privativa do Presidente da República.

\section{Os parlamentos nos foros de negociação internacional}

A influência dos Parlamentos nas relações internacionais vem ampliandose em razão da crescente participação de seus membros em organizações parlamentares de âmbito regional e internacional, tais como a União Interparlamentar e o Parlamento Latino-Americano.

A par dessa tendência, é possível identificar-se também um interesse maior entre os parlamentares pelos rumos que tomam as relações internacionais. Tal interesse decorre do fato de que tais relações já não mais se resumem às grandes questões bélicas e estratégicas. Com efeito, após o fim da guerra fria, a agenda internacional volta-se essencialmente para o comércio e os investimentos. Por conseguinte, as decisões concernentes às relações internacionais vêm produzindo cada vez maiores e mais profundos impactos sobre a estrutura produtiva no interior dos Estados-nações.

Possivelmente por essa razão, e dada a transcendência dos temas em discussão, capazes de afetar a própria sobrevivência de certos setores produtivos do país, os parlamentares têm mostrado interesse em integrar as delegações brasileiras encarregadas de negociações em foros regionais e multilaterais, como a ALCA e a Organização Mundial do Comércio (OMC). Também o Poder Executivo tem mostrado maior flexibilidade com relação a essa participação, consciente da importância de se legitimar, por meio da presença de parlamentares como observadores nas delegações, as decisões tomadas em tais foros. Sabemos que, entre os temas em discussão na Organização Mundial do Comércio, estão questões como a agrícola, informática, propriedade intelectual, e outras capazes de afetar profundamente os esforços de estabilização e desenvolvimento envidados pelo país. O mesmo ocorre nas discussões em curso no âmbito da ALCA, que vêm abordando temas como compras governamentais e serviços, temas estes destinados a ocupar o topo da agenda econômica internacional em futuro não muito distante.

O caso do Mercosul é sui generis, uma vez que a participação parlamentar foi prevista nos próprios tratados constitutivos do bloco: o de Assunção, de 1991, e o Protocolo de Ouro Preto, firmado em dezembro de 1994. 
Concluindo, é patente o crescente anseio de participação da sociedade civil no processos decisórios internacionais. Exemplo dessa tendência são os movimentos populares contrários à globalização presentes inicialmente em Seattle, por ocasião da fracassada Conferência Ministerial da Organização Mundial do Comércio (OMC), que lançaria a Rodada do Milênio ${ }^{12}$, e mais recentemente em Washington, quando da reunião do Fundo Monetário Internacional e do Banco Mundial ${ }^{13}$. As raízes de tais manifestações estão, sem dúvida alguma, no chamado déficit democrático a caracterizar decisões capazes de provocar profundos impactos no dia a dia do cidadão comum. Daí a necessidade de criação de mecanismos que permitam a participação do Parlamento no processo decisório levado a cabo nos foros internacionais.

A presença de parlamentares nos foros negociadores, como observadores, e a atuação das Comissões de Relações Exteriores de ambas as Casas do Congresso Nacional de forma pró-ativa no que tange às conferências agendadas pelas Nações Unidas e outros órgãos internacionais emprestariam maior visibilidade ao processo decisório internacional. Tendo em vista a recente aprovação do calendário de implantação da ALCA na cúpula de Quebec, caberia, a partir de agora, uma ativa participação do Parlamento brasileiro, por meio da realização de debates e audiências públicas. Isso deveria ser feito com a presença de representantes do Ministério das Relações Exteriores, das universidades e da sociedade civil, no sentido de melhor explorar os meios mais oportunos. Dessas reuniões, que possibilitariam o exame e a discussão do tema em pauta, poderiam resultar propostas e recomendações ao Itamaraty, com vistas a subsidiar a posição brasileira nas negociações pontuais que ocorrerão até 2005.

Tais iniciativas para uma maior participação do Parlamento na formulação da política externa brasileira outorgariam às decisões tomadas nos foros internacionais um novo patamar de legitimidade.

Maio de 2001

\section{Notas}

1 Ver REZEK, Francisco. Direito Internacional Público. São Paulo: Saraiva, 1991, p. 68.

2 Idem, op. cit., p. 69.

3 Idem, op. cit., p. 70.

4 Idem, op. cit., p. 73.

5 CERVO, Amado Luiz \& MAGALHÃES, José Calvet de. Depois das Caravelas: as relações entre Portugal e Brasil 1808-2000. Brasília: Editora Universidade de Brasília, 2000, p. 173.

6 Ver DEUTSCH, Karl. Análise das Relações Internacionais. Brasília: Editora Universidade de Brasília, 1978. 
7 Art. 90, incisos II e III do Regimento Interno do Senado Federal.

8 Union Parlementaire. Les Parlements dans le Monde Bruxelles. Le Centre International de Documentation Parlementaire de l'Union Interparlementaire, vol. II, 1987, p. 1446.

9 Idem, op.cit., p. 1446.

10 GRIFFITH, Ernest S.. O Sistema Americano de Governo. Rio de Janeiro: Editorial Nórdica, 1983, p.162.

11 CORWIN, Edward S.. A Constituição Norte-Americana e seu Significado Atual. Rio de Janeiro: Jorge Zahar Editor, 1986.

12 Realizada em 30 de novembro e 01 de dezembro de 1999.

13 Reuniões de abril de 2000.

Resumo

A competência legal do poder legislativo na execução da política exterior é descrita pelo autor. $O$ parlamento brasileiro tem tido participação relativamente pequena na formulação da política externa. Tal fato influenciou na demora das conquistas democráticas do país neste final de século.

\section{Abstract}

The autor describes the legal competence of legislative in executing the Brazilian foreign policy. Brazilian National Congress has had little participation in the formulation of foreign policy. This fact contributed to delay the democratic conquests of Brazil in the end of this century.

Palavras-chave: Parlamento. Política Exterior. Key words: National Congress. Foreign Policy. 